This chapter explores the implications of the new educational paradigm from a technical standpoint and proposes a constructivist-aware approach to best leverage its significance.

\title{
Toward Education 3.0: Pedagogical Affordances and Implications of Social Software and the Semantic Web
}

\author{
Mark Allison, Lynn Marie Kendrick
}

As we move toward our identity as a knowledge-based society, advancements in Internet and mobile-related technologies have had a significant impact on educational institutions, relegating those who fail to embrace the innovations to the ranks of the sidelined. Education has largely assumed a reactionary approach to advancements in technology with little planning within or standardization of pedagogical constructs. We have a unique opportunity to proactively integrate the next planned transformation of the Internet, termed Web 3.0, into existing pedagogical models. Web 3.0 promises to alleviate the concerns associated with the data explosion currently underway by making the Internet more "machine friendly," This intelligent web promises a semantic overlay of constructs using metadata (data about data). In this position paper we explore implications of the new paradigm from a technical standpoint and propose a constructivistaware approach to best leverage its significance. Specifically, we propose a set of core competencies for the new paradigm in Internet technology and draft a specification for an autonomous software agent for the semantic web platform.

\section{Introduction}

Spurred by unprecedented advancements in the areas of computation, networking, and storage, Internet-based tools and services have undergone tremendous growth within recent years. At its onset, this interconnection of networked machines was characterized by filtered information typically uploaded by technology professionals. This read-only modality of the early Internet sparked educational efforts in learning management systems; 
however, this technology was typified by limited response susceptibility and involved in essence, one-way broadcasts (Reiser 2001). Driven by user demand and facilitated by advances in network-based computational and storage technologies, Web 1.0 transitioned to Web 2.0, which is also referred to as the read-write web (McManus 2005). Novice users were now capable of sending newly created or synthesized knowledge to the cloud. The difference between Web 1.0 and 2.0 is illusive as this technology has evolved in a nondiscrete, nonuniform manner (Cormode 2008). By having seemingly unlimited capacity, Web 2.0 became a beacon for social software data; the Internet began to be defined by the collective intelligence of its citizens.

The proliferation of new social software toolsets was in part responsible for the data explosion termed big data (Manyika et al. 2011). This big data is typified by enormous datasets whose computational and storage requirements are in excess of traditional approaches. To put this phenomenon in perspective, consider the following: In 2012 there were 294 billion emails sent each day (Radicati and Hoang 2011), 230 million tweets (Dugan 2011), and 100 terabytes of data uploaded to Facebook daily (Winterberry Group 2012). This vast dataset is relatively unstructured and so massive that much of its potential application to education is untapped. Significant human effort is required to access correct, relevant data and this is primarily accomplished under the auspices of major commercial search engines that may store and share private consumer data as a byproduct. There exists the need for a more tailored approach to knowledge discovery in this era.

What we have seen is the resurgence of artificial intelligence concerns employed to tame and make sense of this data. Statistical machine learning and other data mining techniques are being employed to distill knowledge and add structure to this data; however, taming the unbridled growth of data raises concerns as to the sustainability of these solutions. One of the promising developments is the introduction of a semantic web. This semantic web calls for an ontological structure to data, which has tremendous possibilities for teaching and learning if leveraged appropriately. We will assume the definition of the Web 3.0 concept as an amalgamation of earlier Web 2.0 technologies overlaid with the semantic web. This semantic overlay promises fast on-demand access to relevant data; in this context we look at the impact on our cardinal actors-the educator and the student.

We have seen a lackluster acceptance of the affordances of these technologies within the education realm. This phenomenon is not isolated to our field. The success of the adaptation of technology within any entity is dependent on factors along three dimensions: planning, evaluation, and training (Desikan and Ramesh 2006). Planning ensures that the organization has the relevant internal support systems and the understanding that initiatives do assure near future results. The second dimension, evaluation, 
pertains to fitting the technology to the application context. It is vital that we do not make the mistake of fitting the course objectives and outcomes to the available technology. The third dimension is that of training. Training applies not only to the how-tos of leveraging the technology but also to the why, when, and where.

The domain of this discourse is the underlying technologies pertaining to education with a slant toward the constructivist approach, which views learning as a social activity. Using a scientific grounding in constructivist theory, this position paper presents an exploration of the impact of the primary components of Web 3.0, social networking and the semantic web, on current pedagogical models and proposes apropos methodologies to leverage the technology in higher education teaching and learning. It is the authors' intent to provoke introspection and petition the teaching and learning community to generate discussions surrounding the next generation of our Internet.

Specifically our contributions are:

1. A proposed set of learner competencies for Web 3.0; and

2. An informal specification for learner-centric educational agent architecture capable of leveraging the utilities of the semantic web.

The remainder of the paper is structured as follows: In the following section we present motivation and key concepts as background significant to presenting our position. The third section discusses the core competences required of our students and the fourth proposes an educational agent architecture. We conclude our position by a summary and intent of future research work.

\section{Background}

To effectively present the affordances of Web 3.0 technologies as they apply to education, we present background on the key technologies and pedagogical elements within our domain of discourse. We first present the Web 3.0 concept using indicative scenarios; then we provide a summary of the constructivist approach. The section concludes with a cursory treatment of Web 2.0.

What Is Web 3.0? Web 3.0 is an umbrella term signifying the addition of the semantic web to Web 2.0 Internet applications such as wikis, blogs, and other social media constructs. The term is credited to Tim Berners-Lee in his work The Semantic Web (Berners-Lee et al. 2001). The current state of the Internet (Web 2.0) is an explosion of unorganized data, which has forced the development of more efficient ways of finding information. The growth of this unorganized data has spawned the era of big data technologies. These methods employ some earlier artificial intelligence techniques such as statistical machine learning to make sense or derive 
Figure 9.1. Simple RDF Example Showing Inference Rules

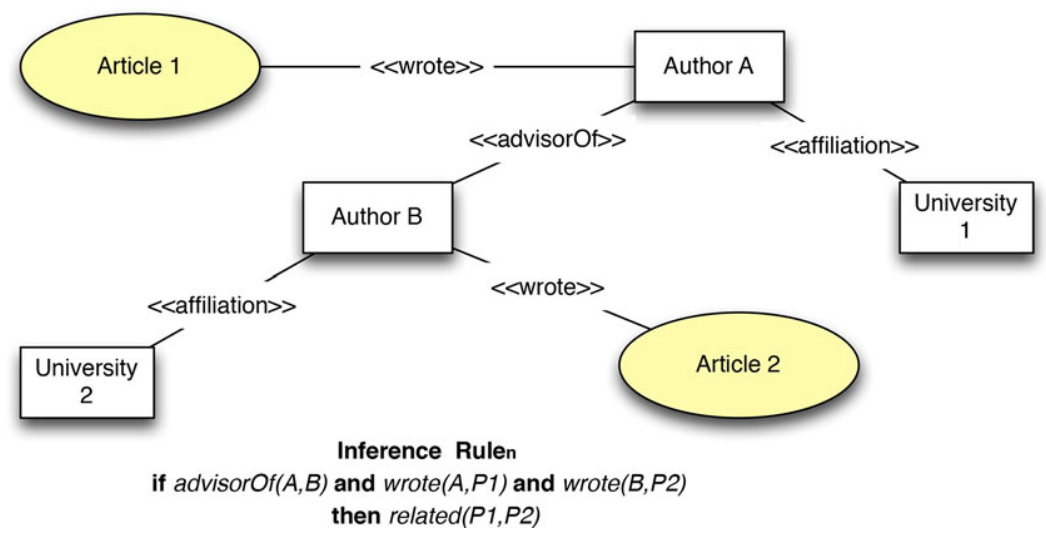

knowledge from this data. As this data continues to grow unabridged it will cause increased difficulty in accessing the desired information. More time will be spent to get at that which is desired.

The semantic web promises structured pathways for information access and increases the web's capacity to support directed processing by machines. The present web technology is designed for human information consumption. Although research is being conducted to assess the meaning of web data according to context, to a machine there are few or no constructs to understand that which is being accessed.

With the addition of semantic tags, software agents as human proxies will have the capability to perform much of tedious search duties on behalf of their student or human counterpart. With the addition of agent technology the student will now be able to focus on more immediate concerns of learning. We expand our discussion of learning agent technology in the fourth section. The semantics of the particular website will be determined by its RDF or Resource Description Framework. The application of RDF to web content is nontrivial. Because the critical aspect of this new paradigm is machine-readable content, it is important for nonexpert content authors to have the capability to easily build semantic web-enabled artifacts. To accomplish this vision, markup tools that allow for ontology design must be employed.

Illustrative Scenarios. In a possible scenario our student employs a search engine to find articles related to a particular subject. The engine responds by generating thousands of web content artifacts based on the keyword search, most of which have no significance and require our student to manually sift through this data.

In a second scenario, our student communicates her needs of finding related works to her educational agent. Figure 9.1 illustrates a simple 
ontological relationship between two articles and forms the basis of this walkthrough. The agent first encounters Article $\mathbf{1}$ at first pass. Using the semantic overlay the agent finds the author, Author A, and inspects his relationships. His/her affiliation has no relevance to the task; there are no applicable inference rules. However Article $\mathbf{2}$ is referenced in inference rule $n$ and states that any article written by a second author, Author B, will be related to Article $\mathbf{1}$ and therefore will be of significance to the student. The end result is a connection between two items made by an automaton, which would otherwise require human intervention and scrutiny.

The Constructivist Approach. Credited to Jean Piaget, constructivism is an epistemological concept based on the idea that learning and the creation of new knowledge is based on, and biased by, an individual's unique experiences and mental schema (Wadsworth 1996). We have chosen to adopt and integrate this approach as it supports our view of learning as social and active. Both these dimensions are directly affected by the technological advances that are the subject of our discourse. Another component of constructivist theory that influences our model is the emphasis given to the study of activities that challenge and engage the learner through constructs such as a zone of proximal development (ZPD). Learning is considered a social activity fostered by deep knowledge creation concepts such as Socratic dialogue and active learning communities (Vygotsky 2012). The following section expands on ZPD within the context of its relationship to social software.

Social Software Affordances. The positive role of the application of social software to education has been well researched (Alexander 2006; Ferdig 2007; McLoughlin and Lee 2007). McLoughlin and Lee (2007) propose that social software tools facilitate learning through communication and networking, collaborative feedback, and social interaction.

Vygotsky described the concept of a zone of proximal development (ZPD), which is the difference between that which learners can grasp on their own and that which can be achieved with the assistance of an educator or in collaboration with a capable peer. The collaboration aspect of the ZPD is that which may be most affected by social software.

The role of educators is to enrich this zone to facilitate individualized learning (Tudge 1992). This enrichment may be achieved via effective instructional scaffolding, creating temporary constructs that may be social in nature to facilitate learning within the ZPD (Pea 2004). Collaborative activities should minimize competition yet facilitate individual accountability (Johnson et al. 1991). In addition, the educator has to bolster the learner's sense of her potential for success as a motivation for learning (Von Glasersfeld 1989).

The read-write web affords students the opportunity to publish their work. This is significant as this publication increases motivational levels and achievements (Richardson 2005). By publishing, the student is forced to be self-critical and seek feedback from the social network. Table 9.1 
Table 9.1. Prevalent Social Software Technologies

\begin{tabular}{|c|c|c|}
\hline Category & Example & Educational Application \\
\hline Content Management & wikis, blogs, YouTube & Crowdsourcing knowledge \\
\hline $\begin{array}{l}\text { Conferencing } \\
\quad \text { (multiple modalities) }\end{array}$ & $\begin{array}{l}\text { Skype, ooVoo } \\
\text { Twiddla, Vyew } \\
\text { Huddle }\end{array}$ & $\begin{array}{l}\text { Synchronous communication of } \\
\text { information and concepts } \\
\text { Void of geographical } \\
\text { boundaries }\end{array}$ \\
\hline Relationship Management & $\begin{array}{l}\text { Facebook, Myspace } \\
\text { Twitter, Bebo, Tumblr }\end{array}$ & $\begin{array}{l}\text { Asynchronous communication } \\
\text { Social networking }\end{array}$ \\
\hline $\begin{array}{l}\text { Social Learning } \\
\text { Management System }\end{array}$ & TOPYX, IBM Kenexa & Learning platform \\
\hline Polls / Q\&A & $\begin{array}{l}\text { Yahoo answers } \\
\text { Poll Anywhere, Survey } \\
\text { Monkey }\end{array}$ & $\begin{array}{l}\text { Users pose questions and solicit } \\
\text { feedback. Research tool }\end{array}$ \\
\hline RSS Feeds & The New York Times & Access to latest developments \\
\hline
\end{tabular}

presents a sampling of prevalent social software technologies and how they have been applied in the classroom. The affordances of this technology cannot be understated. It is a medium for learners to articulate mental constructs and communicate concepts in a manner that has never before been available in human history.

\section{Core Competencies Within the New Learning Ecology}

The new environment insists we revisit and challenge legacy competencies in order to address the gap between academia and societal demands. Our world has become far removed from the three R's of the industrial era. We will focus our discourse along two dimensions; the perspective of the learner and that of the facilitator to learning.

Learner's Perspective. With the advent of Web 3.0 and the pervasiveness of information we propose a set of learner competencies appropriate for this new paradigm. These competencies should be addressed by the student without technological augmentation. We reduce the scope of this discussion to those competencies that are distinctly most applicable.

Management of the Learning Process. The need for learner autonomy in this knowledge-based society is unprecedented. The traditional concept of the classroom and the educator-dominated model are no longer applicable. The information will be ubiquitous, available on any mobile device connected to the Internet. By blurring geographical and temporal boundaries of the classroom, the time to learn becomes the responsibility of the learner. Becoming more capable in time management as it applies to learning is a core competency for learner success. 
Scrutiny and Filtering of Sources. Knowledge in the context of the digital era is flavored by opinions and belief (Dede 2008). Learners need to be mindful and prioritize the relevance of knowledge sources.

Collaboration vis-á-vis the Digital Self. With the advent of Web 2.0, we have spawned digital representations of ourselves that interact with others in our absence (Zhao 2005). The careful management of the digital self is a nontrivial issue because it may affect employment and career advancement opportunities as employers and educational institutions now routinely incorporate this element in decision-making processes. Prospective collaborators and cohort members will be interacting with and will make assumptions based on this proxy.

Problem Solving. The role of problem solving in the higher education curriculum is the subject of much scientific investigation within various disciplines (Allison and Joo 2014). In the workplace of the knowledge-based society there is an emphasis on solving complex tasks in teams. Not only is the aforementioned collaborative component important, but so is problem solving within the context of the team.

Facilitator's Perspective. The competencies presented in the previous section lie within the realm of the learner. This does not mean that the role of the educator remains static. The role of the educator transitions from a lecturer to a facilitator. We now propose Web 3.0 competencies for the educator in the enhanced role of learning facilitator.

Understand the Audience. Educators should understand that their millennial audience was raised in this technological era and can more easily multitask; the divide between student and educator needs to be acknowledged and managed.

Look to Nontraditional Feedback Mechanisms. The classroom of Web 3.0 extends beyond the geographic boundaries and as such need to be managed differently. Within the face-to-face classroom meeting space, the educator may provide instant feedback via emotional queues as simple as a smile or raised eyebrow. This additional modality is absent within the extended classroom and ways to supplement asynchronous text-based communication should be explored.

In computer mediated communications research supports the use of emoticons (e.g., Q) as a means to portray social motive and context (Derks, Bos, and Grumbkow 2007; Walther and D'Addario 2001). Advancements in classroom technology has allowed for unprecedented realtime feedback using classroom response systems or "clickers".

Establish Clear Communication Protocols and Assessment Criteria. With the infusion of technology and the blurring of temporal and spatial boundaries to learning, the environment tends to lack focus and structure. By establishing clear expectations regarding acceptable ways to communicate and how assessment will be handled is pivotal to providing structure. Again, with the constructivist approach the social setting is critical. 
Learner participation in a mistake-managed environment is a key scaffolding construct.

\section{Artificial Autonomous Educational Agents}

The semantic web will allow learners to customize search proxies that are able to mine data and return on-demand knowledge as directed. The specification proposed for the semantic web Berners-Lee et al. (2001) call for a defined meaning or semantics of key terms attached to datasets. To enable automated reasoning Berners-Lee proposes knowledge representation that is distributed and powerful enough to describe complex objects. The target of the semantic web is semantic data and documents. He goes on to propose that computers should have access not only to the structured data but to inference rules to assist in automated reasoning, e.g., how do different concepts relate to each other.

The careful dissenter may remark that powerful search engines have sufficient capability to allow the student to effectively find the required content. Although this is partially true, our position is that the utility and capabilities of a personalized web agent capable of traversing the semantic web may produce more pointed data and suggestions given a more intimate knowledge of the student's needs. This requires the agent to be capable of learning. An issue with search engines is that they are designed for generality-to please all the people all the time. The artificial web agent would be expert in the individual student's domain of interest, not simply education but even the student's major discipline.

James Hendler (1999) has tasked computer science researchers by proposing the ideal Internet agent as having the following capabilities:

- Communicative. The agent should be capable of effective communication with its user. As such the needs of the student should be easily conveyed to the agent as goals. Agents may also be required to interact with other agents.

- Capable. This requires the agent to be able to take action rather than assume the passive role of an advisor. We do, however, believe that the advisory aspect of the agent should not be totally set aside.

- Autonomous. With minimal supervision the agent should be capable of acting on behalf of the student.

- Adaptive. This item will require the effective learning of the students preferences and may even involve ethical and legal aspects. Agents will purport to be the learner's digital self in its undertakings. In accord with our vision, we propose additional nonfunctional requirements for our educational agent.

- Secure. The agent as specified incorporates personal data regarding our student from preferences and authentication information to possibly 
Figure 9.2. The Educational Agent Architecture



credit card information used to purchase articles. It is paramount that this data is not compromised.

- Ubiquitous. The agent should be mobile and available on multiple platforms, particularly mobile devices. In order for the technology to maximize engagement, it will have to be available at learning moments.

- Nonintrusive. The user should not be interrupted or put off by the agent. The agent should work seamlessly as a background activity.

Figure 9.2 shows the generalized architecture of the Education agent derived from a general model of learning agents proposed by Russel and Norvig (2003). The semantic web is signified as a cloud on the far right. This translates to the environment within which the agent operates. The semantic web is acted upon and perceived via the retrieval and navigation elements respectively. Separate from its core data retrieval functionality, the Retrieval element will also acquire any new inference rules and supply them to the Ontology Inference Engine. The Ontology Inference Engine recommends new paths for navigation based on the planners interpretation of the user requests. External inputs to the agent are the Student Attributes, which is a repository of our students' characteristics and preferences, and the Student Requests, which will be translated to the agent's goals. The critic assesses how well 
the agent performs its task based on the criteria of the learner attributes. Feedback is given to the learning element whose task it is to recommend improvements to the planner. We have intentionally described the architecture of the agent at a very high level so as not to constrain its implementation.

\section{Concluding Remarks}

In this paper we have presented a constructivist aware set of competencies that we propose will be key success factors as the learner encounters Web 3.0. In addition, we specified a general architecture for an educational agent to assist the learner. We intend to further this research by implementing the proposed agent architecture and conducting empirical studies surrounding its utility and efficacy in education.

\section{References}

Alexander, B. 2006. "Web 2.0: A New Wave of Innovation for Teaching and Learning?" Educause Review 41 (2): 32.

Allison, M., and S. F. Joo. 2014. "Revisiting Polya's Approach to Foster Problem Solving Skill Development in Software Engineers." In 9th International Conference on Computer Science Education, 379-384. New York: IEEE.

Berners-Lee, T., J. Hendler, O. Lassila, et al. 2001. "The Semantic Web." Scientific American 284 (5): 28-37.

Cormode, G., and B. Krishnamurthy 2008. Key Differences Between Web 1.0 and Web 2.0. First Monday, 13 (6).

Dede, C. 2008. "Theoretical Perspectives Influencing the Use of Information Technology in Teaching and Learning." In International Handbook of Information Technology in Primary and Secondary Education, edited by J. Voogt and G. Knezek, 43-62. New York: Springer.

Derks, D., A. E. Bos, and J. von Grumbkow. 2007. "Emoticons and Social Interaction on the Internet: The Importance of Social Context." Computers in Human Behavior 23 (1): 842-849.

Desikan, S., and G. Ramesh. 2006. Software Testing: Principles and Practice. Delhi, India: Pearson Education India.

Dugan, L. 2011. "230 Million Tweets per Day, 50 Million Daily Users and Other Twitter Stats." Social Times, September 9.

Ferdig, R. E. 2007. "Editorial: Examining Social Software in Teacher Education." Journal of Technology and Teacher Education 15 (1): 5-10.

Hendler, J. 1999. "Is There an Intelligent Agent in Your Future?" Nature, March 11.

Johnson, D. W. et al. 1991. Cooperative Learning: Increasing College Faculty Instructional Productivity. [ASHE-ERIC Higher Education Report No. 4]. Washington, DC: Association for the Study of Higher Education; ERIC Clearinghouse on Higher Education.

Manyika, J., M. Chui, B. Brown, J. Bughin, R. Dobbs, C. Roxburgh, and A. H. Byers. 2011. Big Data: The Next Frontier for Innovation, Competition, and Productivity. Washington, DC: McKinsey Global Institute.

McLoughlin, C., and M. J. Lee. 2007. "Social Software and Participatory Learning: Pedagogical Choices with Technology Affordances in the Web 2.0 Era." In ICT: Providing 
Choices for Learners and Learning. Proceedings ASCILITE Singapore 2007, 664-675. Tugun, Australia: Australasian Society for Computers in Learning in Tertiary Education.

McManus, R. 2005. Web 2.0 Is Not About Version Numbers or Betas. Read/WriteWeb, August 6. http://readwrite.com/2005/08/06/web_20_is_not_a.

Pea, R. D. 2004. "The Social and Technological Dimensions of Scaffolding and Related Theoretical Concepts for Learning, Education, and Human Activity." Journal of the Learning Sciences 13 (3): 423-451.

Radicati, S., and Q. Hoang. 2011. Email Statistics Report, 2011-2015. Palo Alto, CA: The Radicati Group. http://www.radicati.com/wp/wp-content/uploads/2011/05/Email -Statistics-Report-2011--2015-Executive-Summary.pdf.

Reiser, R. A. 2001. "A History of Instructional Design and Technology. Part I: A History of Instructional Media." Educational Technology Research and Development 49 (1): 53-64.

Richardson, W. 2005. "The Educator's Guide to the Read/Write Web." Educational Leadership 63 (4): 24.

Russell, S. J., and P. Norvig. 2003. Artificial Intelligence: A Modern Approach. 2nd ed. Columbus, OH: Pearson Education.

Tudge, J. 1992. Vygotsky, the Zone of Proximal Development, and Peer Collaboration: Implications for Classroom Practice. In Vygotsky and Education: Instructional Implications and Applications of Sociohistorical Psychology, edited by L. C. Moll, 155-172. Cambridge, UK: Cambridge University Press.

Von Glasersfeld, E. 1989. "Cognition, Construction of Knowledge, and Teaching. Synthese 80 (1): 121-140.

Vygotsky, L. S. 2012. Thought and Language. Cambridge, MA: MIT Press.

Wadsworth, B. J. 1996. Piaget's Theory of Cognitive and Affective Development: Foundations of Constructivism. White Plains, NY: Longman Publishing.

Walther, J. B., and K. P. D'Addario. 2001. "The Impacts of Emoticons on Message Interpretation in Computer-Mediated Communication." Social Science Computer Review 19 (3): 324-347.

Winterberry Group. 2012. From Information to Audiences: The Emerging Marketing Data Use Cases. White Paper. http://www.iab.net/media/file/FromInformatonToAudiences -AWinterberryGroupWhitePaper-January2012.pdf.

Zhao, S. 2005. "The Digital Self: Through the Looking Glass of Telecopresent Others." Symbolic Interaction 28(3): 387-405.

MARK ALLISON is an assistant professor of computer science at the University of Michigan-Flint. He received his PhD in computer science from Florida International University.

LYNN MARIE KENDRICK is the dean of academics at West Coast University in Miami. She received her EdD from St. Thomas University. 